\title{
Indução de Resistência em Tomateiro por Extratos Aquosos de Lentinula edodes e Agaricus blazei contra Ralstonia solanacearum
}

\author{
Ricardo F. Silva, Sérgio F. Pascholati \& Ivan P. Bedendo \\ Departamento de Entomologia, Fitopatologia e Zoologia Agrícola, ESALQ, Universidade de São Paulo, Cx. Postal 09, CEP \\ 13418-900, Piracicaba, SP, Brasil, e-mail: rferrari_silva@yahoo.com.br; sfpascho@esalq.usp.br; ipbedend@esalq.usp.br
}

Autor para correspondência: Ivan Paulo Bedendo

SILVA, R.F., PASCHOLATI, S.F. \& BEDENDO, I.P. Indução de resistência em tomateiro por extratos aquosos de Lentinula edodes e Agaricus blazei contra Ralstonia solanacearum. Fitopatologia Brasileira 32:189-196. 2007.

\begin{abstract}
RESUMO
O presente trabalho foi conduzido com o objetivo de avaliar o efeito dos extratos aquosos dos cogumelos Lentinula edodes e Agaricus blazei e do indutor de resistência acibenzolar-S-metil (ASM) no controle da murcha bacteriana em tomate (Lycopersicon esculentum Mill.), bem como investigar o modo de ação destes produtos na atividade protetora, através de alterações na atividade de determinadas enzimas. Extratos aquosos dos cogumelos e o ASM foram testados na inibição do crescimento da bactéria in vitro. Em casa-de-vegetação, plantas foram tratadas com diferentes doses dos extratos e com ASM $(0,05 \mathrm{~g} / \mathrm{L})$, dois dias antes da inoculação. As avaliações foram efetuadas com base na severidade da doença e determinação da atividade de algumas enzimas. Os isolados de A. blazei e L. edodes, bem como o ASM, não exerceram efeito inibitório direto no crescimento da bactéria. Quanto à indução de resistência, o isolado Le-96/17 de L. edodes na concentração de $10 \%(\mathrm{v} / \mathrm{v})$ e o ASM reduziram significativamente a ocorrência de murcha. As atividades de quitinase, fenilalanina amônia-liase e polifenoloxidase não foram alteradas para a maioria dos tratamentos, porém foi constatado um aumento na atividade de quitinase nas plantas tratadas com ASM. Para a peroxidase, os tratamentos ASM, Abl-26 e Le96/17 ocasionaram aumentos na atividade da enzima e, com base nos resultados, o cogumelo L. edodes e o ASM apresentam potencial para reduzir a murcha bacteriana provavelmente através da indução de resistência.
\end{abstract}

Palavras-chave adicionais: murcha bacteriana, proteínas-RP, resistência induzida.

\begin{abstract}
Induction of resistance in tomato plants by aqueous extracts of Lentinula edodes and Agaricus blazei against Ralstonia solanacearum

This work deals with the effect of aqueous extracts from the mushrooms Lentinula edodes and Agaricus blazei and the inducer of resistance acibenzolar-S-methyl (ASM) on the control of bacterial wilt in tomato (Lycopersicon esculentum Mill.), as well as investigating changes in enzyme activities. Aqueous extracts of the mushrooms and ASM were tested for inhibition of bacterial growth in vitro. Plants were treated with different concentrations of the extracts and with ASM two days before inoculation in greenhouse conditions. The evaluations were based upon disease severity and activity of some enzymes. In general, the isolates of A. blazei and L. edodes, as well as ASM, did not inhibit in vitro bacterial growth. In treated plants, the isolate Le-96/17 $10 \%(\mathrm{v} / \mathrm{v})$ of $L$. edodes and ASM significantly reduced bacterial wilt. Chitinase, phenylalanine ammonia-lyase and polyphenoloxidase activities were not changed for most of the treatments; however, increased chitinase activity was verified in plants treated with ASM. The ASM, Abl-26 and Le-96/17 treatments increased peroxidase activity in plants and, based upon the results, L. edodes mushroom and ASM both exhibit potential to reduce bacterial wilt in tomato plants, probably by inducing resistance.
\end{abstract}

Additional keywords: bacterial wilt, PR-proteins, induced resistance.

\section{INTRODUÇÃO}

As bactérias vêm assumindo importância crescente entre os patógenos que afetam espécies de plantas de expressão econômica na agricultura brasileira, causando elevadas perdas, embora não existam estatísticas precisas (Araújo et al., 2003; Kimura \& Carmo, 1995; Lopes \& Quezado-Soares, 1997; Romeiro, 1995). Dentre as doenças que afetam a cultura do tomateiro, a murcha causada por

Parte da Tese de Doutorado do primeiro autor. ESALQ, Universidade de São Paulo. Piracicaba SP. 2007.
Ralstonia solanacearum (Smith) Yabuuchi et al. tem promovido perdas relevantes em culturas instaladas nas diversas regiões brasileiras. A doença tem sido assinalada desde o Estado do Amazonas até o Rio Grande do Sul e, dependendo das condições ambientais, os prejuízos podem ser totais (Batista \& Guedes, 1981). Pelo fato deste patógeno atuar no sistema vascular, ser habitante do solo e estar associado a um grande número de espécies botânicas, o controle da doença se torna extremamente difícil (Lopes \& Reifschneider, 1999).

Novas alternativas de controle têm sido estudadas para promover a redução da severidade de doenças em diversas culturas, sendo a indução de resistência um método 
potencial. Esta indução pode ser efetiva contra diversos patógenos, incluindo virus, bactérias e fungos, sendo ativada por indutores bióticos ou abióticos (Baysal et al., 2003; Bonaldo et al., 2005; Ryals et al., 1996). O agente indutor não atua diretamente sobre o patógeno ou é transformado em algum agente antimicrobiano, mas ele sensibiliza a planta a ativar seus mecanismos de defesa em resposta à presença de um patógeno (Conrath et al., 2002). Esses mecanismos podem envolver enzimas como peroxidase, $\beta$-1,3-glucanase, quitinase, fenilalanina amônia-liase e polifenoloxidase (Cavalcanti et al., 2005).

Dentre os indutores abióticos, o ácido salicílico (AS) e seus análogos são os mais importantes. Um exemplo é o acibenzolar-S-metil (ASM), que tem se revelado um potente ativador de resistência sistêmica adquirida (RSA), conferindo proteção em condições de campo contra um amplo espectro de patógenos de diversas espécies de plantas cultivadas (Gorlach et al., 1996). Os agentes bióticos, sejam estes microrganismos viáveis ou inativados, podem também ativar mecanismos de defesa da planta (Stangarlin \& Pascholati, 1994). Entre estes agentes, os cogumelos Lentinula edodes (Berk.) Pegler e Agaricus blazei Murrill apresentam substâncias no basidiocarpo e no micélio com potencial para o controle de fitopatógenos. Assim, Pacumbaba et al. (1999) demonstraram que o lixiviado micelial de L. edodes impediu a ocorrência de murcha bacteriana em tomateiro provocada por $R$. solanacearum e murcha de feijoeiro causada por Curtobacterium flaccumfaciens pv. Alaccumfaciens (Hedges) Collins \& Jones, quando aplicado em substrato previamente infestado com as bactérias. Di Piero (2003) verificou a proteção de plantas de tomate contra Xanthomonas vesicatoria (Doidge) Vauterin et al. utilizando extratos de um isolado de $A$. blazei, que reduziu significativamente a severidade da bacteriose quando aplicado a $10 \%(\mathrm{v} / \mathrm{v})$ e 5 dias antes da inoculação das plantas. Trabalhando com o filtrado da cultura de L. edodes, Komemushi et al. (1995) observaram atividade antimicrobiana sobre bactérias Gram positivas, Gram negativas e sobre fungos. Posteriormente, foi isolado um composto antibacteriano formado por um álcool $\beta$-fenetil e lentinamicin, que estava presente em culturas líquidas de micélio (Komemushi et al., 1996).

Em razão da importância da murcha para a cultura do tomateiro e do potencial efeito de extratos de $L$. edodes e $A$. blazei sobre a indução de resistência, o presente trabalho teve por objetivos avaliar o efeito indutor de extratos aquosos dos cogumelos e do ASM na resistência do tomateiro à murcha bacteriana e determinar a atividade das enzimas peroxidase, quitinase, fenilalanina amônia-liase e polifenoloxidase, como respostas de defesa.

\section{MATERIAL E MÉTODOS}

Obtenção e manutenção dos fitopatógenos e das plantas

Utilizou-se o isolado Rs47 de $R$. solanacearum, obtido junto à empresa Sakata Seeds Sudamerica Ltda. Para a realização dos ensaios, o isolado foi cultivado no meio de tetrazólio (Kelman, 1954), com incubação por 48 h a $28 \pm 2{ }^{\circ} \mathrm{C}$. O isolado bacteriano foi preservado em tubos de ensaio contendo o meio nutriente-ágar (NA) coberto por óleo mineral esterilizado e em água destilada esterilizada (Wakimoto et al., 1982), em temperatura ambiente ou na geladeira. Sementes do híbrido de tomate Hib. F1 Carmen, cedidas pela empresa Sakata Seed Sudamerica Ltda, foram semeadas em bandejas de poliestireno de 128 células contendo o substrato agrícola Plantmax ${ }^{\circledR}$ (Eucatex). As plantas foram mantidas em casa-de-vegetação com média de temperatura dia/noite de $30 / 22{ }^{\circ} \mathrm{C}$, umidade relativa $\geq 60 \%$ e fotoperíodo de aproximadamente 12 horas.

\section{Obtenção dos extratos aquosos de $L$. edodes e $A$. blazei}

Os cogumelos foram produzidos no Departamento de Produção Vegetal (Módulo de Cogumelos), da Faculdade de Ciências Agronômicas - UNESP/Botucatu. Para obtenção do extrato bruto dos isolados Le-96/22 e Le-96/17 de L. edodes e Abl-26 e Abl-29 de A. blazei, o pó seco de basidiocarpo recebeu $14 \mathrm{~mL}$ de água destilada por grama. Após $24 \mathrm{~h}$ de incubação a $4{ }^{\circ} \mathrm{C}$, a suspensão foi filtrada em papel de filtro comum e centrifugada a $20.000 \mathrm{~g}$ por $25 \mathrm{~min}$ (Di Piero, 2003). Para os testes realizados in vitro, os extratos aquosos foram esterilizados por filtragem (diâmetro do poro $=0,2 \mu \mathrm{m})$, sob condições assépticas, sendo posteriormente armazenados a $4^{\circ} \mathrm{C}$ até serem usados.

\section{Efeito in vitro dos extratos aquosos dos cogumelos e do ASM sobre $R$. solanacearum}

Tubos de ensaio contendo água destilada esterilizada receberam ASM (0,05 g/L; Bion ${ }^{\circledR}$, Syngenta) e os extratos aquosos dos isolados de $L$. edodes (Le-96/17 e Le-96/22) e $A$. blazei (Abl-26 e Abl-29), obtendo-se concentrações finais de $5,10,15$ e $20 \%$ (v/v). O tratamento controle foi representado por tubos contendo somenteágua. Posteriormente, adicionouse $1 \mathrm{~mL}$ de suspensão bacteriana em cada tubo, de modo que a concentração final fosse de $10^{8} \mathrm{ufc} / \mathrm{mL}$. O ensaio foi conduzido com cinco repetições por tratamento, onde cada tubo representou uma repetição. Os tubos foram mantidos no escuro a $28 \pm 2{ }^{\circ} \mathrm{C}$ por $24 \mathrm{~h}$ sendo que, posteriormente, alíquotas de $300 \mu \mathrm{L}$ de cada tubo foram pipetadas em placas de Petri contendo o meio nutriente-ágar (NA) e espalhadas por toda a superfície do meio com o auxílio de uma alça de Drigalsky. As placas foram novamente mantidas no escuro a $28 \pm 2{ }^{\circ} \mathrm{C}$, por $48 \mathrm{~h}$. A avaliação dos resultados foi efetuada com a suspensão bacteriana obtida em cada placa, pela adição de $20 \mathrm{~mL}$ de água destilada, através de leitura em espectrofotômetro a $550 \mathrm{~nm}$, obtendo-se o valor da unidade de absorbância (U.A.) por $\mathrm{mL}$. Este ensaio foi realizado duas vezes.

\section{Proteção de plantas de tomate em casa-de-vegetação}

Plantas de tomate com 20 dias após a semeadura foram tratadas, ainda na bandeja, com os extratos aquosos dos cogumelos, com o ASM ou com água, através da rega do substrato agrícola Plantmax ${ }^{\circledR}(10 \mathrm{~mL} /$ planta $)$. Após dois 
dias do tratamento, as plantas foram retiradas da bandeja e sacudidas para retirar o substrato aderido as raízes, sendo então realizada a inoculação da bactéria através do corte das raízes com tesoura e imersão destas raízes por 10 minutos em suspensão bacteriana calibrada para $10^{8} \mathrm{ufc} / \mathrm{mL}$ (Lopes, 1981). As plantas foram transplantadas para vasos contendo um novo substrato esterilizado, composto de solo, esterco de curral e areia (1:1:1) e mantidas em casa-de-vegetação com temperatura dia/noite de $33 / 24{ }^{\circ} \mathrm{C}$, umidade relativa $\geq 70 \%$ e fotoperíodo de aproximadamente 12 horas.. Foram realizadas 10 repetições/tratamento, onde cada planta representou uma repetição. O delineamento experimental foi o completamente casualizado. As avaliações foram feitas no $5^{\circ}$ e $10^{\circ}$ dias após a inoculação, com base na porcentagem de folhas murchas (número de folhas murchas x 100 / número total de folhas da planta) e peso da matéria fresca e seca. Os tratamentos usados no experimento foram: plantas tratadas com água (T1 e T2); plantas tratadas com ASM na concentração de $0,005 \mathrm{~g} / \mathrm{L}$ (T3); plantas tratadas com Abl-29 na concentração de $10 \%$ e $20 \%$ (T4 e T5); plantas tratadas com Abl-26 na concentração de $10 \%$ e $20 \%$ (T6 e T7); plantas tratadas com Le-96/17 na concentração de $10 \%$ e $20 \%$ (T8 e T9) e plantas tratadas com Le-96/22 na concentração de $10 \%$ e $20 \%$ (T10 e T11).

\section{Determinação da atividade enzimática}

As plantas de tomate foram tratadas com os extratos aquosos dos cogumelos e com ASM, bem como inoculadas com a bactéria $R$. solanacearum de forma idêntica àquela descrita no item anterior. Em cada tratamento foram utilizadas quatro repetições, onde cada planta representou uma repetição, em um delineamento inteiramente casualizado. As amostras consistiram da coleta de todas as folhas de cada planta aos $0,1,2,3,4,7$ e 12 dias após os tratamentos. Os tratamentos utilizados foram: plantas tratadas com água (T1 e T2); plantas tratadas com ASM na concentração de 0,005 g/L (T3 e T4); plantas tratadas com Abl-26 na concentração de $10 \%$ (T5 e T6) e plantas tratadas com Le-96/17 na concentração de $10 \%$ (T7 e T8), sendo que as plantas dos tratamentos pares foram inoculadas com $R$. solanacearum dois dias após os tratamentos.

As amostras coletadas foram maceradas e homogeneizadas em $4 \mathrm{~mL}$ de tampão de acetato de sódio $100 \mathrm{mM}(\mathrm{pH} 5,0)$ e centrifugadas a $20000 \mathrm{~g} / 25 \mathrm{~min}$ a 4 ${ }^{\circ} \mathrm{C}$. Os sobrenadantes foram coletados e armazenados em congelador a $-20{ }^{\circ} \mathrm{C}$, para avaliação do teor de proteínas totais (Bradford, 1976) e atividades enzimáticas.

A atividade de peroxidase foi determinada por método espectrofotométrico direto, através da medida da conversão do guaiacol em tetraguaiacol a $470 \mathrm{~nm}$ (Lusso $\&$ Pascholati, 1999). A reação foi realizada com $0,1 \mathrm{~mL}$ do extrato proteico misturado com $2,9 \mathrm{~mL}$ de uma solução com $250 \mu \mathrm{L}$ de guaiacol e $306 \mu \mathrm{L}$ de peróxido de hidrogênio em $100 \mathrm{~mL}$ de tampão fosfato $0,01 \mathrm{M}(\mathrm{pH} 6,0)$. A atividade da peroxidase foi expressa em unidades de absorbância / min / mg proteína (U.A./ min /mg prot). Para se avaliar a atividade de quitinases utilizou-se a metodologia descrita por Wirth \& Wolf (1990), na qual ocorre a liberação de fragmentos solúveis de quitina carboximetilada marcada com remazol brilhante violeta (CM-Chitin-RBV). Foram utilizados $200 \mu \mathrm{L}$ do extrato proteico misturados com 600 $\mu \mathrm{L}$ de tampão de extração (acetato de sódio $10 \mathrm{mM}, \mathrm{pH} 5,0$ ) e $200 \mu \mathrm{L}$ do substrato CM-Chitin-RBV $\left(2,0 \mathrm{mg} \cdot \mathrm{mL}^{-1}\right)$. Estas amostras foram incubadas a $40{ }^{\circ} \mathrm{C}$ em banho-maria por 20 min, paralisando-se a reação com a adição de $200 \mu \mathrm{L}$ de $\mathrm{HCl}$ 1,0 M. Em seguida, as amostras foram centrifugadas a $4{ }^{\circ} \mathrm{C}$ por $10 \mathrm{~min}$ a $5000 \mathrm{~g}$, procedendo-se então a leitura do sobrenadante em absorbância de $550 \mathrm{~nm}$. Os resultados foram expressos em U.A. / min / mg de proteína.

A atividade de polifenoloxidase foi determinada de acordo com Duangmal \& Apenten (1999), pela mensuração da conversão do catecol em quinona. O substrato utilizado foi composto por catecol $20 \mathrm{mM}$ dissolvido em tampão fosfato de sódio $100 \mathrm{mM}(\mathrm{pH} 6,8)$. Para a reação, que ocorreu a 30 ${ }^{\circ} \mathrm{C}, 900 \mu \mathrm{L}$ do substrato foram misturados com $100 \mu \mathrm{L}$ do extrato proteico. As leituras foram feitas a cada $10 \mathrm{~s}$ a 420 $\mathrm{nm}$ em espectrofotômetro, durante $1 \mathrm{~min}$. O diferencial entre a terceira e a quinta leitura foi utilizado para a determinação da atividade. Os resultados foram expressos em unidades de PPO, sendo que uma unidade foi definida como um incremento de absorbância de 0,001 por min de reação por mg de proteína total.

A atividade de fenilalanina amônia-liase foi determinada pela quantificação colorimétrica do ácido transcinâmico liberado do substrato fenilalanina (Umesha, 2006). A reação continha $100 \mu \mathrm{L}$ do extrato protéico misturado com $400 \mu \mathrm{L}$ do tampão Tris $\mathrm{HCl} 25 \mathrm{mM}(\mathrm{pH} 8,8)$ e com 500 $\mu \mathrm{L}$ de L-fenilalanina (50 mM em tampão Tris $\mathrm{HCl} 25 \mathrm{mM}$, pH 8,8), a qual foi incubada por $2 \mathrm{~h} \mathrm{a} 40^{\circ} \mathrm{C}$. A absorbância das amostras foi determinada a $290 \mathrm{~nm}$, contra tampão de extração, sendo subtraído de cada amostra o valor do controle (controle $=100 \mu \mathrm{L}$ do extrato proteico $+900 \mu \mathrm{L}$ de tampão Tris $\mathrm{HCl} 25 \mathrm{mM}, \mathrm{pH} \mathrm{8,8).} \mathrm{A} \mathrm{atividade} \mathrm{enzimática}$ foi expressa em $\mu \mathrm{g}$ de ácido trans-cinâmico $/ \mathrm{min} / \mathrm{mg}$ de proteína, utilizando uma curva padrão para o ácido.

\section{RESULTADOS}

Efeito in vitro e de proteção de tomateiro em casa-devegetação contra $R$. solanacearum utilizando os extratos dos cogumelos e o ASM

Nos testes in vitro realizados para $R$. solanacearum, o ASM e os extratos aquosos de A. blazei ou L. edodes não promoveram inibição significativa do crescimento da bactéria (dados não mostrados).

$\mathrm{O}$ experimento realizado em casa-de-vegetação, visando avaliar a proteção das plantas de tomate contra $R$. solanacearum, utilizando o indutor acibenzolar-S-metil (ASM) e os extratos aquosos de L. edodes e A. blazei, mostrou que o extrato aquoso do isolado Le-96/17 a $10 \%$ $(\mathrm{v} / \mathrm{v})$ e o ASM proporcionaram menores porcentagens de folhas murchas, em relação aos demais tratamentos. 
Estes dois tratamentos reduziram a severidade da murcha bacteriana em $66,00 \%$ e 53,68 \% respectivamente, em relação a testemunha tratada com água e inoculada com a bactéria (Tabela 1). Dentre os isolados de A. blazei, Abl$2610 \%(\mathrm{v} / \mathrm{v})$ foi o que proporcionou menor porcentagem de folhas murchas. Quanto ao efeito dos tratamentos sobre o peso da matéria fresca e seca, as plantas tratadas com o isolado Le-96/17 a 10 \% (v/v) e com água (testemunha nãoinoculada) tiveram maior peso em relação às plantas tratadas nos demais tratamentos (Tabela 1).

\section{Efeito dos indutores sobre a atividade enzimática}

No ensaio envolvendo a atividade de peroxidases, as plantas tratadas com ASM e Abl-26 e inoculadas com a bactéria tiveram um aumento na atividade enzimática no $7^{\circ}$ e $12^{\circ}$ dia após o tratamento, respectivamente (Figuras $1 \mathrm{~A}$ e 1 B). No caso do tratamento com o extrato de Le-96/17, houve um aumento significativo na atividade de peroxidase nas plantas inoculadas com bactéria apenas no $3^{\circ}$ dia após o tratamento, ou seja, um dia após a inoculação (Figura $1 \mathrm{C}$ ). A atividade de peroxidase aumentou significativamente nas plantas não inoculadas com a bactéria e tratadas com ASM, Abl-26 e Le-96/17, no $3^{\circ}, 7^{\circ}$ e $12^{\circ}$ dias após o tratamento, em relação ao tratamento água (Figura $1 \mathrm{~A}-\mathrm{C}$ ).

Quanto à quitinase, o tratamento de plantas com ASM e inoculadas com RS47 provocou aumento significativo na atividade enzimática no $7^{\circ}$ dia após o tratamento (Figura 2 A). Nos tratamentos conduzidos com os extratos de Abl 26 e Le-96/17 e inoculados com a bactéria foi verificada menor atividade desta enzima em todas as avaliações em relação às plantas tratadas com água e inoculadas com a bactéria, exceto para o material amostrado no $3^{\circ}$ dia após o tratamento com Le-96/17 (Figura 2 C).

A atividade das enzimas fenilalanina amônia-liase e polifenoloxidase em plantas tratadas com os indutores e inoculadas com a bactéria foram menores do que nas plantas tratadas com água e inoculadas com o patógeno (Figuras 3 e 4). No entanto, nas plantas não inoculadas, a atividade destas enzimas foi maior nas plantas tratadas pelos indutores ao $3^{\circ}, 7^{\circ}$ e $12^{\circ}$ dias após o tratamento (Figuras 3 e 4 ).

\section{DISCUSSÃO}

Nos testes conduzidos in vitro, os resultados obtidos foram semelhantes àqueles obtidos por Di Piero \& Pascholati (2004a), onde os isolados de L. edodes utilizados não apresentaram efeito direto in vitro e os isolados de A. blazei chegaram até a estimular o crescimento de Xanthomonas vesicatoria. Entretanto, alguns trabalhos têm mostrado que isolados destes cogumelos podem inibir o crescimento de patógenos. No estudo do efeito inibitório in vitro de quatro linhagens de L. edodes (Le 10, 46, K2, Assai) sobre algumas espécies de fungos filamentosos de importância agrícola como Helminthosporium euphorbiae Hansf., Fusarium solani (Mart.) Sacc. e Phomopsis sojae Lehman e sobre o sorotipo Alagoas do vírus da estomatite vesicular (VSA), Sasaki et al. (2001) observaram que as linhagens K2 e Le10 mostraram-se antagônicas aos fungos e as linhagens 46 e K2 foram eficientes na inibição do VSA. Um lixiviado micelial de um isolado de $L$. edodes também inibiu significativamente o crescimento de diversas bactérias fitopatogênicas como P. syringae pv. glycinea (Coerper) Young, Dye \& Wilkie, P. syringae pv. tabaci (Wolf \& Foster) Young et al., Xanthomonas campestris pv. glycines (Nakano) Dye, Erwinia amylovora (Burril) Winslow et al., Ralstonia solanacearum e Curtobacterium flaccumfaciens pv. flaccumfaciens (Hedges) Collins \& Jones (Pacumbaba et al., 1999).

TABELA 1 - Efeito do acibenzolar-S-metil (ASM), dos extratos aquosos de Agaricus blazei (Abl-26 e Abl-29) e Lentinula edodes (Le-96/17 e Le-96/22), em diferentes concentrações, sobre a ocorrência de folhas murchas de tomateiro e peso da matéria fresca e seca

\begin{tabular}{|c|c|c|c|c|c|}
\hline \multirow[t]{2}{*}{ Tratamentos } & \multicolumn{2}{|c|}{ Folhas murchas (\%) } & \multirow[t]{2}{*}{$\%$ de controle ${ }^{3}$} & \multicolumn{2}{|c|}{ Peso da Matéria } \\
\hline & Dia 5 & Dia 10 & & $\overline{\text { Fresca }(g)}$ & Seca (g) \\
\hline T1 - Água & $0,00 \mathrm{a}^{2}$ & $0,00 \quad \mathrm{c}$ & - & $1,90 \mathrm{a}$ & $0,29 \mathrm{a}$ \\
\hline $\mathrm{T} 2-\mathrm{Rs} 47^{1}$ (inoculada) & $3,33 \mathrm{a}$ & $100,00 \mathrm{a}$ & - & $0,25 \mathrm{~b}$ & $0,10 \quad b$ \\
\hline $\mathrm{T} 3-\mathrm{ASM}$ & $5,44 \mathrm{a}$ & $46,32 \mathrm{~b}$ & 53,68 & $0,91 \quad b$ & $0,13 \quad b$ \\
\hline T4 - Abl-29 10\% & $2,22 \mathrm{a}$ & $67,30 \mathrm{ab}$ & 32,70 & $0,65 \mathrm{~b}$ & $0,14 \quad b$ \\
\hline T5 - Abl-29 20\% & $7,33 \mathrm{a}$ & $70,14 \mathrm{ab}$ & 29,86 & $0,59 \mathrm{~b}$ & $0,13 \quad b$ \\
\hline T6 - Abl-26 10\% & $6,14 \mathrm{a}$ & $61,72 \mathrm{ab}$ & 38,28 & $0,70 \quad b$ & $0,15 \mathrm{~b}$ \\
\hline T7 - Abl-26 20\% & $0,00 \mathrm{a}$ & $80,80 \mathrm{ab}$ & 19,20 & $0,88 \quad b$ & $0,19 \mathrm{~b}$ \\
\hline T8 - Le-96/17 10\% & $1,54 \mathrm{a}$ & $44,00 \mathrm{~b}$ & 66,00 & $2,06 \mathrm{a}$ & $0,29 \mathrm{a}$ \\
\hline T9 - Le-96/17 20\% & $1,55 \mathrm{a}$ & $71,75 \mathrm{ab}$ & 28,25 & $0,69 \mathrm{~b}$ & $0,15 \mathrm{~b}$ \\
\hline T10 - Le-96/22 10\% & $5,12 \mathrm{a}$ & $91,43 \mathrm{ab}$ & 8,57 & $0,64 \mathrm{~b}$ & $0,15 \quad b$ \\
\hline T11 - Le-96/22 20\% & $1,77 \mathrm{a}$ & $82,03 \mathrm{ab}$ & 17,97 & $0,46 \quad b$ & $0,12 \quad b$ \\
\hline
\end{tabular}



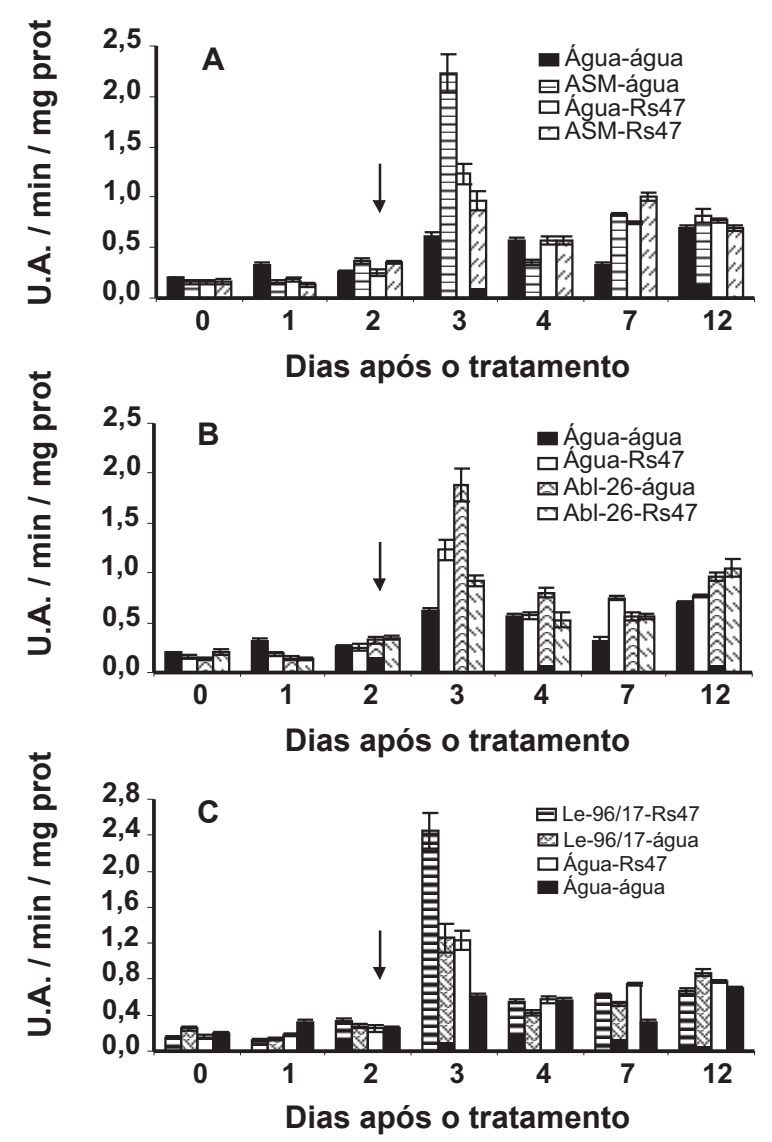

FIG. 1 - Atividade de peroxidase em resposta a aplicação de ASM (A) e dos extratos aquosos de Agaricus blazei Abl-26 (B) e de Lentinula edodes Le-96/17 (C) nas folhas de tomateiro. A seta indica inoculação com $R$. solanacearum (Rs47), no segundo dia após os tratamentos. Barras representam a média \pm desvio padrão.

Em casa-de-vegetação, o isolado Le-96/17 10 \% (v/v) de $L$. edodes e o ASM proporcionaram menor porcentagem de folhas murchas, aos 10 dias após a inoculação. Esse aumento em resistência observado nas plantas não ocorreu devido a uma ação direta dos indutores sobre o patógeno, uma vez que estes tratamentos não apresentaram atividade antibiótica in vitro, o qual é um dos critérios utilizados para se distinguir resistência induzida de outros mecanismos que possam reduzir a doença.

O efeito na redução da severidade da doença proporcionado por indutores também foi demonstrado por Soylu et al. (2003), onde plantas de tomate tratadas com ASM tiveram a severidade da doença causada por $C$. michiganensis subsp. michiganensis (Smith) Davis et al. reduzida em $75 \%$ aos 7 dias após a inoculação, mantendo o mesmo nível de controle até 14 dias após a inoculação. Quando este mesmo indutor foi utilizado visando o controle de $R$. solanacearum em três cultivares de tomateiro, ocorreu uma redução significativa no progresso da doença (Araújo et al., 2005). Já Di Piero \& Pascholati (2004a) observaram
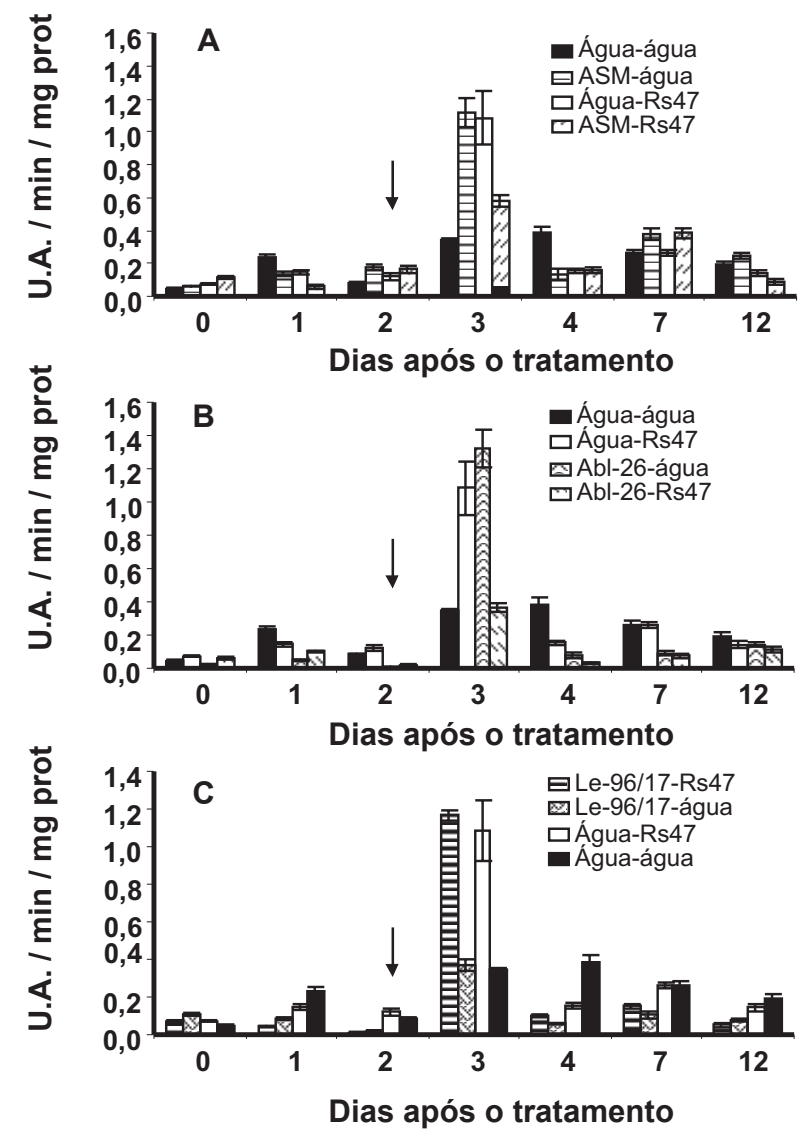

FIG. 2 - Atividade de quitinase em resposta a aplicação de ASM (A) e dos extratos aquosos de Agaricus blazei Abl-26 (B) e de Lentinula edodes Le-96/17 (C) nas folhas de tomateiro. A seta indica inoculação com $R$. solanacearum (Rs47), no segundo dia após os tratamentos. Barras representam a média \pm desvio padrão.

em plantas de tomate que o extrato aquoso do isolado $\mathrm{Abl}$ 99/28 de A. blazei reduziu significativamente a severidade de doença causada por Xanthomonas vesicatoria em casade-vegetação, com uma proteção média de $45 \%$.

Estudando o efeito de indução de resistência de extratos de cogumelos em plantas de pepino contra Colletotrichum lagenaria (Pass.) Ellis \& Halst., Di Piero \& Pascholati (2004b) verificaram que uma mistura de isolados de $L$. edodes reduziu significativamente a severidade da doença, tanto local como sistemicamente. Este efeito sistêmico da indução de resistência verificado neste trabalho também foi observado por Silva et al. (2003), o qual, ao aplicar em tomateiro o acibenzolar-S-metil (ASM) via pulverização foliar ou irrigado no solo contra Xanthomonas vesicatoria, não detectou diferença significativa entre os modos de aplicação do produto, sendo que as duas formas de aplicação proporcionaram proteção das plantas contra a mancha bacteriana, através da ativação dos mecanismos de defesa da planta.

Barretti (2005), em estudos para avaliar o efeito 

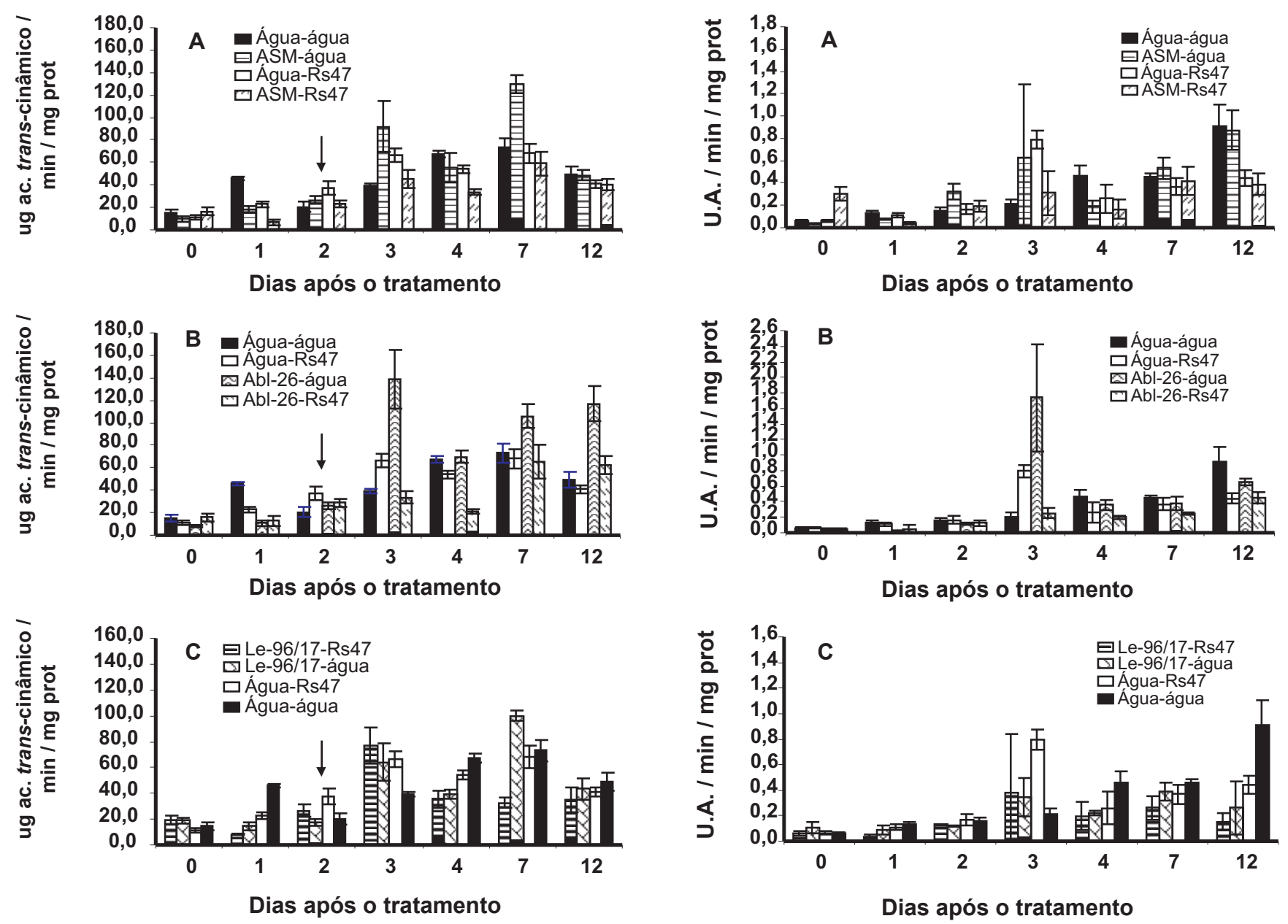

FIG. 3 - Atividade de fenilalanina amônia-liase em resposta a aplicação de ASM (A) e dos extratos aquosos de Agaricus blazei Abl26 (B) e de Lentinula edodes Le-96/17 (C) nas folhas de tomateiro. A seta indica inoculação com $R$. solanacearum (Rs47), no segundo dia após os tratamentos. Barras representam a média \pm desvio padrão.

do ASM no controle de $R$. solanacearum em tomateiro, comprovou que não houve diferença no modo de aplicação do produto, seja por pulverização foliar seja irrigado no solo, mas houve redução significativa da severidade da doença em relação à testemunha não tratada. Os dois modos de aplicação do produto foram igualmente eficazes na proteção do tomateiro contra a murcha. No presente trabalho, os extratos dos cogumelos e o ASM foram aplicados no substrato, sendo também verificado a proteção das plantas de tomate contra a murcha bacteriana nos tratamentos onde foi aplicado o extrato aquoso Le-96/17 de L. edodes e o ASM.

Já as análises bioquímicas, realizadas a partir das folhas, mostraram que a atividade de peroxidase, para os tratamentos Le-96/17 e ASM, foi significativamente maior no $3^{\circ}$ e $7^{\circ}$ dias após o tratamento, respectivamente. Estes níveis de atividade de peroxidase obtidos nas folhas tratadas podem ter contribuído na redução de folhas murchas, uma

vez que estes dois tratamentos foram os melhores em relação aos demais. A participação de enzimas relacionadas à resistência foi evidenciada por Baysal et al. (2003), onde plantas de tomate tratadas com ASM e inoculadas com C. michiganensis subsp. michiganensis exibiram maior atividade de peroxidase aos 5 dias e de quitinase aos 2,3 , 5 e 7 dias após a inoculação com a bactéria. Esse aumento foi correlacionado com a resistência induzida nas plantas de tomate tratadas com ASM. Esta maior atividade de peroxidase e quitinase também foi observada no presente trabalho, aos 7 dias após o tratamento, ou seja, 5 dias após a inoculação, para as plantas tratadas com ASM e inoculadas com $R$. solanacearum.

$\mathrm{Na}$ avaliação da resistência à antracnose de quatro cultivares de feijão, pulverizadas com ácido salicílico ou com um fungo indutor, Campos et al. (2004) verificaram que, avaliando a atividade de peroxidase e polifenoloxidase 
das plantas tratadas, cinco dias após a inoculação com o patógeno, houve um acréscimo na atividade destas enzimas nos tratamentos com ácido salicílico e com o fungo indutor em todas as cultivares. Em plantas de pepino tratadas com extrato aquoso de L. edodes e desafiadas com Colletotrichum lagenaria, Di Piero \& Pascholati (2004b) constataram uma elevação na atividade local e sistêmica de peroxidases no $9^{\circ}$ e $12^{\circ}$ dias após o tratamento, respectivamente (no $3^{\circ}$ e $6^{\circ}$ dia após a inoculação do patógeno). Já para a atividade local e sistêmica de quitinases, não houve diferenças significativas entre quaisquer dos tratamentos após a inoculação com $C$. lagenaria.

A participação das peroxidases e oxidases de polifenóis na resistência induzida de tomateiro contra Xanthomonas vesicatoria foi demonstrada por Cavalcanti et al. (2006), onde após a pulverização das plantas com ASM ou Ecolife ${ }^{\circledR}$, foi evidenciado aumento na atividade destas enzimas logo nas primeiras horas após a pulverização, ocorrendo maior atividade no $5^{\circ}$ dia após a inoculação do patógeno. No presente trabalho ocorreu aumento na atividade de peroxidase e quitinase, mas não ocorreu aumento na atividade de fenilalanina amônia-liase e polifenoloxidase nas plantas tratadas e inoculadas com a bactéria.

A atividade de peroxidase tem sido implicada em uma variedade de processos relacionados com a defesa das plantas, incluindo reação de hipersensibilidade, lignificação e suberização. Nas plantas em geral, como por exemplo, em tomate, a peroxidase é uma das enzimas envolvidas no último passo na lignificação. $\mathrm{O}$ reforço da parede celular da planta por lignina e compostos fenólicos, aumenta a resistência da planta à degradação enzimática por patógenos e atua como barreira mecânica ao ingresso de toxinas, bem como a penetração física (Nicholson \& Hammerschmidt, 1992).

Para as enzimas fenilalanina amônia-liase, polifenoloxidase e quitinase, ocorreu uma diminuição da atividade nas plantas tratadas com os indutores e inoculadas com a bactéria, exceto para o tratamento ASM para quitinase. Esta redução na atividade de algumas enzimas também foi verificada por Osswald et al. (2004), que estudando o patossistema sorgo - Colletotrichum graminicola (Ces.) G.W. Wilson, observaram que apesar da indução na produção de fitoalexinas ser diretamente proporcional ao aumento da dose de ASM, ocorreu uma redução na atividade das enzimas ß-1,3-glucanase e quitinase.

Os extratos aquosos de A. blazei e L. edodes possuem substâncias antibióticas e/ou substâncias capazes de agir como elicitores de respostas de resistência em algumas plantas (local e sistemicamente), mostrando assim potencial para o uso no controle alternativo de patógenos de plantas (Eira et al., 2005). A indução de resistência apresenta-se como componente de um manejo integrado, somandose, por exemplo, ao emprego de cultivares com um nível de resistência satisfatório a $R$. solanacearum. Finalmente, a ausência de efeito in vitro do ASM e dos extratos de cogumelos sobre a bactéria, a alteração na atividade de enzimas e a menor ocorrência de folhas murchas, em função dos tratamentos com ASM e Le-96/17, sugere que esses agentes atuam sobre as plantas de tomate através da indução de resistência.

\section{AGRADECIMENTOS}

Agradecemos a Profa. Marli T.A. Minhoni pelo fornecimento dos basidiocarpos dos isolados de Lentinula edodes e de Agaricus blazei, à Coordenação de Aperfeiçoamento de Pessoal de Nível Superior (CAPES) pela bolsa concedida e à Sakata Seeds Sudamerica Ltda pela disponibilização das sementes de tomate e do isolado bacteriano.

\section{REFERÊNCIAS BIBLIOGRÁFICAS}

ARAUJO, J.S.P., GONÇALVES, K.S., OLIVEIRA, B.C., RIBEIRO, R.L.D. \& POLIDORO, J.C. Efeito do acibenzolarS-metil sobre a murcha-bacteriana do tomateiro. Horticultura Brasileira 23:5-8. 2005.

ARAUJO, J.S.P., ROBBS, C.F. \& RIBEIRO, R.L.D. Manejo integrado de fitobacterioses de importância econômica no Brasil. Parte 1. In: Luz, W.C., Fernandes, J.M.C., Prestes, A.M. \& Picinini, E.C. (Eds.) Revisão Anual de Patologia de Plantas. Passo Fundo RS. 2003. pp. 107-131.

BARRETTI, P.B. Efeito do acibenzolar-S-metil (ASM) na proteção contra a murcha bacteriana do tomateiro. Tese de Doutorado. Lavras MG. Universidade Federal de Lavras. 2005.

BATISTA, M.F. \& GUEDES, A.L.C. Problemas fitopatológicos da cultura do tomateiro. Brasília: EMBRAPA-CNPH, 1981.

BAYSAL, O., SOYLU, E.M. \& SOYLU, S. Induction of defencerelated enzymes and resistance by the plant activator acibenzolarS-methyl in tomato seedlings against bacterial canker caused by Clavibacter michiganensis ssp. michiganensis. Plant Pathology 52:747-753. 2003.

BONALDO, S.M., PASCHOLATI, S.F. \& ROMEIRO, R.S. Indução de resistência: noções básicas e perspectivas. In: Cavalcanti, L.S., Di Piero, R.M., Cia, P., Pascholati, S.F., Resende, M.L.V. \& Romeiro, R.S. (Eds.) Indução de resistência em plantas a patógenos e insetos. Piracicaba SP. FEALQ. 2005. pp. 11-28.

BRADFORD, M.A. A rapid and sensitive method for the quantification of microgram quanties of protein utilizing the principle of protein-dye binding. Analytical Biochemistry 72:248254. 1976.

CAMPOS, A.D., FERREIRA, A.G., HAMPE, M.M.V., ANTUNES, I.F., BRANCÃO, N., SILVEIRA, E.P., OSÓRIO, V.A. $\&$ AUGUSTIN, E. Atividade de peroxidase e polifenoloxidase na resistência do feijão à antracnose. Pesquisa Agropecuária Brasileira 39:637-643. 2004.

CAVALCANTI, L.S., BRUNELLI, K.R. \& STANGARLIN, J.R. Aspectos bioquímicos e moleculares da resistência induzida. In: Cavalcanti, L.S., Di Piero, R.M., Cia, P., Pascholati, S.F., Resende, 
M.L.V. \& Romeiro, R.S. (Eds.) Indução de resistência em plantas a patógenos e insetos. Piracicaba SP. FEALQ. 2005. pp. 81-124.

CAVALCANTI, F.R., RESENDE, M.L.V., ZACARONI, A.B., RIBEIRO JUNIOR, P.M., COSTA, J.C.B. \& SOUZA, R.M. Acibenzolar-S-metil e Ecolife $\mathbb{R}$ na indução de respostas de defesa do tomateiro contra a mancha bacteriana (Xanthomonas vesicatoria). Fitopatologia Brasileira 31:372-380. 2006.

CONRATH, U., PIETERSE, C.M.J. \& MAUCH-MANI, B. Priming in plant pathogen interactions. Trends in Plant Science 7:210-216. 2002.

DI PIERO, R.M. Potencial dos cogumelos Lentinula edodes (Shiitake) e Agaricus blazei (Cogumelo-do-Sol) no controle de doenças em plantas de pepino, maracujá e tomate, e purificação parcial de compostos biologicamente ativos. Tese de Doutorado. Piracicaba SP. ESALQ, Universidade de São Paulo. 2003.

DI PIERO, R.M. \& PASCHOLATI, S.F. Efeitos dos cogumelos Agaricus blazei e Lentinula edodes na interação entre plantas de tomate e Xanthomonas vesicatoria. Summa Phytopathologica 30:57-62. 2004a.

DI PIERO, R.M. \& PASCHOLATI, S.F. Indução de resistência em plantas de pepino contra Colletotrichum lagenarium pela aplicação de extratos de basidiocarpos de Lentinula edodes e de Agaricus blazei. Summa Phytopathologica 30:243-250. 2004 b.

DUANGMAL, K. \& APENTEN, R.K.O. A comparative study of polyphenoloxidases from taro (Colocasia esculenta) and potato (Solanum tuberosum var. Romano). Food Chemistry 64:351-359. 1999.

EIRA, A.F., KANENO, R., RODRIGUES FILHO, E., BARBISAN, L.F., PASCHOLATI, S.F., DI PIERO, R.M., SALVADORI, D.M.F., LIMA, P.L.A. \& RIBEIRO, L.R. Farming technology, biochemistry characterization, and protective effects of culinary-medicinal mushrooms Agaricus brasiliensis S. Wasser et al. and Lentinus edodes (Berk.) Singer: Five years of research in Brazil. International Journal of Medicinal Mushrooms 7:281-299. 2005.

GORLACH, J., VOLRATH, S., KNAUF-BEITER, G., HENGY, G., BECKHOVE, U., KOGEL, K.H., OOSTENDORP, M., STAUB, T., WARD, E., KESSMANN, H. \& RYALS, J. Benzothiadiazole, a novel class of inducers of systemic resistance, actives gene expression and disease resistance in wheat. The Plant Cell 8:629-643. 1996.

KELMAN, A. The relationship of pathogenicity in Pseudomonas solanacearum to colony appearance on a tetrazolium medium. Phytopathology 44:693-695. 1954.

KIMURA, O. \& CARMO, M.G.F. Enfermidades bacterianas do pimentão. Informe Agropecuário 18:66-70. 1995.

KOMEMUSHI, S., YAMAMOTO, Y. \& FUJTA, T. Antimicrobial substance produced by Lentinula edodes. Journal of Antibacterial and Antifungical Agents 23:81-86. 1995.

KOMEMUSHI, S., YAMAMOTO, Y. \& FUJTA, T. Purification and identification of antimicrobial substances produced by Lentinula edodes. Journal of Antibacterial and Antifungal Agents 24:21-25. 1996.

LOPES, C.A. Doenças bacterianas da batata. Informe Agropecuário 7:40-42. 1981.

LOPES, C.A. \& QUEZADO-SOARES, A.M. Doenças bacterianas das hortaliças: diagnose e controle. Brasília: EMBRAPA-CNPH, 1997.

LOPES, C.A. \& REIFSCHNEIDER, F.J.B. Manejo integrado das doenças da batata. Informe Agropecuário 20:56-60. 1999.

LUSSO, M.F.G. \& PASCHOLATI, S.F. Activity and isoenzymatic pattern of soluble peroxidases in maize tissues after mechanical injury or fungal inoculation. Summa Phytopathologica 25:244249. 1999.

NICHOLSON, R.L. \& HAMMERSCHMIDT, R. Phenolic compounds and their role in disease resistance. Annual Review of Phytopathology 30:369-389. 1992.

OSSWALD, W.F., STANGARLIN, J.R., NICHOLSON, R.L., BRUMMER, M., WULFF, N.A., DI PIERO, R.M., PICCININN, E., DI CIERO, L., HOTO, F.V. \& PASCHOLATI, S.F. The effect of acibenzolar-S-methyl on phytoalexin and PR-protein induction on sorghum mesocotyls and on Colletotrichum sublineolum. Summa Phytopathologica 30:415-420. 2004.

PACUMBABA, R.P.; BEYL, C.A. \& PACUMBABA JUNIOR, R.O. Shiitake mycelial leachate supresses growth of some bacterial species and symptoms of bacterial wilt of tomato and lima bean in vitro. Plant Disease 83:20-23. 1999.

ROMEIRO, R.S. Bactérias Fitopatogênicas. Viçosa MG. UFV. 1995.

RYALS, J.A., NEUENSCHWANDER, U.H., WILLITS, M.G., MOLINA, A., STEINER, H. \& HUNT, M.D. Systemic acquired resistance. The Plant Cell 8:1809-1819. 1996.

SASAKI, S.H., LINHARES, R.E.C., NOZAWA, C.M., MONTALVÁN, R. \& PACCOLA-MEIRELLES, L.D. Strains of Lentinula edodes supress growth of phytopathogenic fungi and inhibit Alagoas serotype of vesicular stomatitis virus. Brazilian Journal of Microbiology 32:52-55. 2001.

SILVA, L.H.C.P., RESENDE, M.L.V., SOUZA, R.M., CAMPOS, J.R., \& CASTRO, A.M.S. Indução de resistência contra Xanthomonas vesicatoria em tomateiro por acibenzolar-S-metil. Summa Phytopathologica 29:177-181. 2003.

SOYLU, S., BAYSAL, O. \& SOYLU, E.M. Induction of disease resistance by the plant activator, acibenzolar-S-methyl (ASM), against bacterial canker (Clavibacter michiganensis subsp. michiganensis) in tomato seedlings. Plant Science 165:1069-1075. 2003.

STANGARLIN, J.R. \& PASCHOLATI, S.F. Proteção de plântulas de milho pipoca contra Exserohilum turcicum pelo uso de Saccharomyces cerevisae. Summa Phytopathologica 20:16-21. 1994.

UMESHA, S. Phenylalanine ammonia lyase activity in tomato seedlings and its relationship to bacterial canker disease resistance. Phytoparasitica 34:68-71. 2006.

WAKIMOTO, S., UTATSU, K., MATSUO, N. \& HAYASHI, N. Multiplication of Pseudomonas solanacearum in pure water. Annals of Phytopathological Society of Japan 48:620-627. 1982.

WIRTH, S.J. \& WOLF, G.A. Dye-labelled substrates for the assay and detection of chitinase and lysozyme activity. Journal of Microbiological Methods 12:197-205. 1990. 